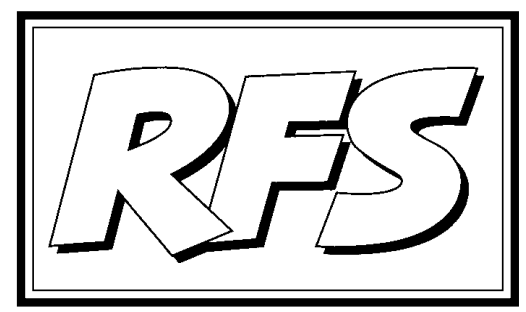

Revista de Fomento Social, 57 (2002), 65-84

\title{
Los microcréditos: una posibilidad de trabajo y de mejora económica para la familia
}

Ma Cruz LACALLE CALDERÓN ${ }^{1}$

Actualmente los microcréditos se están configurando como un instrumento que está permitiendo el acceso a un puesto de trabajo y a una fuente regular de ingresos a muchos hombres y mujeres de los sectores más desfavorecidos de los países del tercer mundo. Esta realidad, que es especialmente cierta en el caso de miles de mujeres, que de otra manera no tendrían ninguna posibilidad de mantener, de alimentar o de mejorar el bienestar de sus familias, es precisamente la que se analiza en este artículo. Para ello, comenzamos, en primer lugar, estudiando la dificultad que millones de personas, especialmente mujeres, encuentran a la hora de conseguir un puesto de trabajo con un sueldo digno. Concretamente, se mostrará el número de hombres y mujeres que permanecen atrapados en el círculo vicioso de la pobreza dentro del sector informal de sus econo-

1 Doctora en CC. Económicas, y profesora titular de la Universidad Alfonso X El Sabio. 
mías, entre los prestamistas usureros y un empleo muy precario.

En segundo lugar, se analiza la manera en que los microcréditos permiten solucionar este problema, es decir, cómo éstos posibilitan el acceso a una fuente regular de ingresos con la que mejorar el nivel de bienestar de la familia. Para ello se estudiará este instrumento: su origen, sus características y los requisitos que deben cumplir las instituciones que trabajan con los mismos si desean tener éxito y alcanzar el objetivo planteado.

Para terminar, una vez analizado el problema y su posible solución, se destaca uno de los aspectos más característicos dentro del mundo de las microfinanzas: la gran diferencia que existe entre la utilización que los hombres y las mujeres hacen de este instrumento para conseguir una fuente regular de ingresos. Los datos confirman que los microcréditos se dirigen fundamentalmente a las mujeres y que éstas son las que hacen un mejor uso en beneficio de sus familias. Este último apartado muestra por qué las mujeres son las protagonistas dentro de este nuevo escenario.

\section{El sector informal}

\subsection{Composición y origen del sector informal}

Algunas teorías del desarrollo han tratado de demostrar que uno de los motivos por los que en muchos países subdesarrollados no se inicia un proceso de crecimiento económico sostenido es porque una gran parte de los recursos humanos de dichos países no estaban dispuestos a trabajar. Hoy se sabe que esto no es cierto. Los pobres del tercer mundo llevan mucho tiempo luchando por salir de la pobreza. Son millones las personas en todo el mundo que, al no encontrar ninguna posibilidad de empleo en el sector estructurado de la economía, debido a su falta de preparación, tratan de crear sus propias fuentes de ingresos. En los países subdesarrollados, cada día un mayor número de personas pobres produce una amplia variedad de bienes en talleres improvisados, fabrican cigarrillos con sus manos para vender los por las calles, hacen sillas de bambú o venden frutas y verduras en las laderas de cualquier camino. Todos estos pequeños "negocios" o microempresas, que dan ocupación muy precaria a una gran parte de la población de menores ingresos, conforman un singular sector de la economía conocido como el Sector Informal. 
Este sector informal se define como un conjunto heterogéneo de actividades productivas, cuyo elemento común es emplear a personas que no podrían encontrar trabajo en el sector moderno de la economía, y que tienen una baja relación capital-trabajo debido a la falta de acceso a los factores de producción complementarios de la mano de obra, obteniendo como consecuencia escasos ingresos laborales. Para sobrevivir en el mercado, estas unidades productivas deben vender a precios competitivos, lo que normalmente les obliga a reducir la remuneración de la fuerza laboral (Mezzera, 1998). Este sector comprende actividades como comercio minorista, vendedores de comidas y bebidas en vías públicas, carpinteros, reciclados informales de basura, comercialización de productos de contrabando, etc. Los trabajadores de este sector llaman a estas actividades "negocios", pero en realidad nunca aparecerán en una hoja de balance contable o comercial, ni en ningún informe bancario. Nunca rellenarán una declaración de impuestos y, por supuesto, nunca aparecerán engrosando la producción nacional de su país (Aslanbeigui, 1995:66). Se mantienen gracias a su esfuerzo y creatividad, procurando garantizar al menos su propia subsistencia. Por tanto, estos micronegocios o microempresas son pequeñísimas unidades económicas que operan al margen de las regulaciones oficiales.

\subsection{Importancia del sector informal}

Aunque no es posible precisar la dimensión del sector informal, fundamentalmente porque la gran mayoría de las microempresas que lo forman operan al margen de regulaciones y registros oficiales, puede afirmarse que su participación en las economías nacionales de los países más atrasados es muy elevada. Al inicio de la década pasada, según datos del Comité de Ayuda al Desarrollo de la OCDE, entre un 30 y un $70 \%$ de la población económicamente activa de los países en vías de desarrollo estaba ocupada en el sector informal. En las áreas urbanas, cada día más trabajadores -a veces hasta el $50 \%$ de la población activa- tienen su microempresa. En las áreas rurales, la gran mayoría de las familias trabajan simultáneamente en la agricultura y alguna actividad microempresarial.

El sector informal acoge a millones de trabajadores. Como se puede observar en los datos de los cuadros 1 y 2 , su importancia varía considerablemente entre países y también entre continentes.

En la gran mayoría de los países del tercer mundo, el sector informal se 
encarga de generar un porcentaje muy importante de los bienes y servicios que componen el producto interior. Concretamente, en los países africanos, este sector genera entre el 19 y $51 \%$ del PIB, porcentajes superiores a los alcanzados en los países deAmérica Latina y de Asia, excepto para el caso de Indonesia. De acuerdo con la Comisión Económica para América Latina y el Caribe (CEPAL, 1993), alrededor del 30\% de la población económicamente activa en América Latina trabaja en el sector informal.

\section{CUADRO 1}

\section{Sector Informal}

\begin{tabular}{|lcc|}
\hline Pais & Año & $\begin{array}{c}\text { Tamaño dol Soctor Informal } \\
\text { (medido en \% sobre el PIB de su pais) }\end{array}$ \\
\hline Africa & & \\
\hline Burundi & 1990 & 25 \\
Congo & 1984 & 33 \\
Egipto & 1986 & 18 \\
Gambia & 1983 & 51 \\
Mali & 1990 & 40 \\
Zarnbia & 1960 & 39 \\
\hline Latino América & & \\
\hline Brasil & 1990 & 18 \\
Costa Rica & 1984 & 15 \\
Honduras & 1990 & 26 \\
Jamaica & 1988 & 25 \\
Mexico & 1992 & 16 \\
Uruguay & 1985 & 16 \\
Venezuela & 1992 & 23 \\
\hline Asla & & 49 \\
\hline Indonesia & 1985 & 12 \\
Iraq & 1987 & 30 \\
R. Coreal & 1989 & 19 \\
Malasia & 1986 & 16 \\
Tailandia & 1990 & \\
\hline
\end{tabular}

Fuente: Naciones Unidas (1995b) 


\section{CUADRO 2}

\section{Sector Informal}

\begin{tabular}{|c|c|c|c|c|}
\hline \multirow[t]{2}{*}{ Pais } & \multirow[t]{2}{*}{ Año } & \multicolumn{3}{|c|}{$\begin{array}{l}\text { Tamaño del Sector Informal } \\
\text { (medifo en } \% \text { sobre el total de la poblseión activa) }\end{array}$} \\
\hline & & Total & Mujerses & Hombres \\
\hline \multicolumn{5}{|l|}{\begin{tabular}{|l|} 
Alrica \\
\end{tabular}} \\
\hline Burundi & 1990 & 27 & 32 & 21 \\
\hline Congo & 1994 & 41 & 57 & 25 \\
\hline Egipto & 1986 & 12 & 3 & 21 \\
\hline Gambia & 1983 & 44 & 62 & 25 \\
\hline Mali & 1980 & 40 & 34 & 45 \\
\hline Zambia & 1006 & 51 & 72 & 29 \\
\hline \multicolumn{5}{|c|}{ Latino America } \\
\hline Brasil & 1000 & 20 & 21 & 19 \\
\hline Costa Rica & 1994 & 14 & 8 & 19 \\
\hline Honduras & 1980 & 28 & 34 & 21 \\
\hline Jamaica & 1968 & 27 & 28 & 25 \\
\hline Maxico & 1902 & 19 & 15 & 22 \\
\hline Unuguay & 1985 & 16 & 15 & 17 \\
\hline Venezuela & 1992 & 22 & 21 & 23 \\
\hline \multicolumn{5}{|l|}{ Asia } \\
\hline Indonesia & 1925 & 53 & 65 & 41 \\
\hline Iraq & 1se/ & y & b & 11 \\
\hline R. Corea & 1000 & 45 & 41 & 40 \\
\hline Malasia & 1986 & 21 & 24 & 17 \\
\hline Taliandia & 1000 & 10 & 24 & 12 \\
\hline
\end{tabular}

Fuente: Naciones Unidas (1995b)

Los trabajadores del sector informal representan una parte muy relevante de la fuerza laboral. En el cuadro 2, se puede observar la importancia del mismo en los tres continentes, medida como porcentaje de la población 
activa de cada país. Estos porcentajes varían entre el 12 y el $51 \%$ en África, entre el 14 y el $28 \%$ en América Latina y entre el 8 y el $53 \%$ en Asia.

En cuanto al volumen de mujeres y de hombres que componen el sector informal, los datos del cuadro 2, confirman una mayor participación femenina. Según el Fondo de Población de las Naciones Unidas, como resultado de la crisis económica durante el pasado decenio, el sector informal pasó de concentrar el 30\% en 1980 a concentrar el $58 \%$ de la fuerza de trabajo en 1990 , y ha sido la mujer fundamentalmente la que tuvo que acudir a esta estrategia de supervivencia (Aslanbeigui, 1995). Además, según datos de las Naciones Unidas (1995a:115), en to dos los países africanos estudiados, excepto Egipto, más de un tercio de las mujeres económicamente activas que trabajan fuera de la agricultura, estaban ocupadas en el sector informal de sus países. En siete países latinoamericanos estas cifras ascendían al 20\% de las mujeres económicamente activas, y en algunos países de Asia como la República de Corea e Indonesia, Ilegaban a alcanzar el $41 \%$ y el $65 \%$ respectivamente. Se puede por lo tanto afirmar que la mujer se encuentra desproporcionadamente representada en el sector informal (Lycette, 1988:39).

1.3. ¿Por qué estas personas permanecen atrapadas en el círculo vicioso de la pobreza?

La reducida productividad que caracteriza a todas estas actividades económicas informales, no es el resultado de falta de trabajo, esfuerzo o iniciativa por parte de los microempresarios (González, 1996), sino más bien, de una serie de problemas o limitaciones con los que se enfrentan las microempresas. Entre estas restricciones, la más importante es la falta de acceso a los servicios financieros (Lycette, 1988; Labie, 1998; Liedholm y Mead, 1987; Sethuraman, 1988; Alarcón Costa, 1990).

"iTienes que tener dinero para hacer dinero!". Como bien expresa este simple principio mercantil, para llevar a cabo cualquier actividad productiva se necesita disponer de recursos financieros (Hunt, 1982:12). Las microempresas nacen con el objetivo de generar un flujo de ingresos futuros. Ahora bien, para satisfacer ese objetivo es necesario hacer inversiones en materias primas y bienes de equipo entre otros, y dichas inversiones no pueden llevarse a cabo si no se dispone de recursos financieros. Además, si una empresa no dispone de recursos, no podrá aprovechar las oportunidades productivas que se le presenten, por lo que le será difícil incrementar sus 
ingresos. Se puede afirmar, por lo tanto, que el acceso a los recursos financieros es una condición necesaria aunque no suficiente, para que cualquier pequeño negocio pueda aumentar sus niveles de productividad y beneficios.

En términos generales, los recursos financieros pueden provenir de dos fuentes. De la propia capacidad de ahorro, es decir, de la autofinanciación, que precisamente no es lo más normal en el caso de los más pobres de la sociedad, o de la financiación externa, la cual a su vez puede tener dos orígenes:

1. Los intermediarios financieros formales, principalmente la banca comercial.

2. Los intermediarios financieros informales, que son todos aquellos agentes económicos o instituciones que operan en los mercados financieros al margen de las regulaciones y controles gubernamentales movilizando capital desde los ahorradores hacia aquellos que lo necesitan. Pues bien, las dos principales fuentes de financiación informal son por un lado los parientes, amigos y vecinos, y por otro, los prestamistas individuales, comúnmente conocidos como usureros.

La realidad a la que se tienen que enfrentar la gran mayoría de las microempresas del sector informal y los más desfavorecidos del tercer mundo, es la dificultad para encontrar servicios financieros en condiciones adecuadas a sus necesidades. Por un lado, el crédito de la banca siempre les ha sido negado a los más pobres, al no cumplir los requisitos de garantía. El lema de los bancos siempre ha sido: Los pobres carecen de recursos suficientes para sobrevivir, por lo tanto, no se les puede otorgar un crédito. Al carecer de acceso a los servicios financieros formales, la única salida de muchos era pedir ayuda los prestamistas informales. Bien a los familiares o bien a los usureros. En cuanto a los primeros, si bien es cierto que componen una importante fuente de crédito informal en el tercer mundo, el problema es que como la ayuda suele provenir de patrimonios muy reducidos, ésta no siempre está disponible. En cuanto a los segundos, los usureros, son aquellos que conceden préstamos al margen de la legalidad. No poseen ningún tipo de registro de los préstamos concedidos, trabajan en la calle y conocen muy bien a su clientela potencial. Estos prestamistas normalmente prestan dinero a muy corto plazo y cobran unos intereses muy superiores a los del mercado. Lo más usual es pagar entre un 2 y $4 \%$ al día, pero a veces, se llega a pagar hasta un 10\% diario (Carpintero, 1999:112) con lo que sus préstamos siempre 
resultan demasiado costosos. Aunque es cierto que estos usureros prestan a la población más pobre servicios de crédito en condiciones muy favorables: no exigen garantías colaterales (la garantía suele ser la propia persona), conceden crédito muy rápido, muy sencillo, sin burocracias ni papeleos y con plena libertad en la utilización del dinero, no obstante, este tipo de crédito tiene sus inconvenientes, de los cuales, el más importante es los elevadísimos tipos de interés que habrá que devolver. Intereres que muchas veces les explotan y empobrecen aún más, de manera que nunca serán capaces de liberarse de la necesidad de los mismos (Teka, 1997).

Por todos estos motivos, en la mayoría de las ocasiones, los más pobres y los microempresarios encuentran grandes dificultades para adquirir el capital necesario para sus negocios, perdiendo así las oportunidades para el crecimiento de sus actividades y la posibilidad de mejorar su bienestar y el de sus familias.

Como respuesta a este problema, durante las tres últimas décadas, ha surgido un gran número de programas, cuyo principal objetivo ha sido prestar servicios microfinancieros a los más desfavorecidos. Unos cuantos especialistas en finanzas y en las teorías del desarrollo desafiaron los axiomas básicos de la banca comercial, que afirmaban que prestar a los más pobres era demasiado arriesgado y costoso como para resultar rentable, y pusieron en marcha estos programas de apoyo a los clientes más pobres. Las instituciones dedicadas a este tipo de actividades son las llamadas Instituciones Microfinancieras o Instituciones dedicadas a los microcréditos.

En el próximo apartado expondremos más ampliamente el concepto y las características de esta nueva alternativa de financiación, más conocida como los microcréditos.

\section{Los microcréditos}

\subsection{Origen}

El padre de los microcréditos fue Muhammad Yunus, profesor de economía en la universidad de Chittagong (Bangladesh). Yunus después de doctorarse en Estados Unidos y volver a su país, comenzó a preocuparse por los elevadísimos niveles de pobreza y por la situación económica que empeoraba cada día. En 1974, Yunus decidió estudiar cómo vivían y se comportaban 
los pobres de las zonas rurales de Bangladesh. Decidió averiguar por qué algunas personas, trabajando 12 horas al día, los 7 días de la semana, no tenían suficiente comida que llevar a sus mesas. Durante 1975-76, Y unus se dedicó, a estudiar directamente las causas de la miseria rural. Un día mientras entrevistaba a una mujer hizo un gran descubrimiento:

\begin{abstract}
Laili Begum era una pobre mujer que vivía en la pequeña aldea de J obra. Laili trabajaba durante todo el día haciendo banquetas de bambú, pero seguía atrapada en la miseria. Laili no tenía capital propio, por lo que para comprar la materia prima, el bambú, tenía que pedir dinero prestado al comerciante que compraba su mercancía, el cual se aprovechaba de la situación, pagándole precios muy bajos por las banquetas y dejándole apenas un taka por día -varias pesetas por día. Con la ayuda de sus estudiantes de doctorado, Yunus descubrió que muchos otros también se encontraban bajo las mismas condiciones de vida. Su pobreza no era el resultado de falta de inteligencia o de vaguería. Era un problema estructural: falta de capital (Jolis, 1996:3).
\end{abstract}

Yunus se dio cuenta de que el sistema en el que vivían esas personas no les permitía ahorrar ni una sola peseta para mejorar su nivel de vida. Los prestamistas informales se aprovechaban de la situación pidiendo elevados tipos de interés que oscilaban al rededor del 10\% mensual (Hossain, 1988:23), llegando incluso a veces al $10 \%$ semanal. De esta forma, por muy duro que estas personas trabajaran, nunca podrían salir del nivel de subsistencia. Necesitaban tener acceso a capital, aunque fuera en pequeñas cantidades (J olis, 1996).

Después de hablar con Laili, Yunus se ofreció a prestarle el equivalente a 30 dólares. Esto significaba que ella podría comprar el bambú sin necesidad de pedir dinero prestado al comerciante, y por lo tanto, podría exigir un mejor precio por sus banquetas. Lo mismo hizo con las otras 42 personas que se encontraban en la misma situación que Laili. Alentado por el éxito de su experimento, en 1976, puso en marcha un proyecto de investigación, cuyo objetivo era el diseño de un programa de crédito para los más pobres que fuese viable. Rompiendo con todas las tradiciones y los principios sagrados de la banca comercial, Yunus comenzó a otorgar préstamos únicamente a los más pobres, sin exigir garantías ni fiadores. Así nacieron los microcréditos.

\title{
2.2. Concepto
}

Según la Conferencia Internacional sobre Microcréditos que tuvo lugar en Washington D.C. del 2 al 4 de febrero de 1997 los microcréditos son: 
“Programas de concesión de pequeños créditos a los más necesitados de entre los pobres para que éstos puedan poner en marcha pequeños negocios que generen ingresos con los que mejorar su nivel de vida y el de sus familias".

En términos generales, se trata de una herramienta para reducir las diferencias en el acceso a los recursos financieros, y como consecuencia, para alcanzar mejores condiciones de vida para los más pobres de la sociedad. El objetivo final es hacer llegar el dinero, en condiciones muy favorables, a pequeños emprendedores de los sectores sociales más desfavorecidos.

La idea central que encierran los microcréditos es conceder pequeños préstamos a los más necesitados, con el único fin de ayudarles a salir del círculo vicioso de la pobreza. De esta manera, ayudando a miles de pequeños microempresarios a crear su propio negocio, crear nuevos puestos de trabajo e incrementar sus ingresos, se puede romper este círculo en el que viven millones de personas, y como consecuencia, llegar a modificar las cifras actuales sobre la pobreza en el mundo.

\subsection{Características}

Las principales características de los microcréditos provienen de su propio nombre y son las siguientes:

- La reducida cuantía de los préstamos. Se trata de pequeñísimas cantidades de dinero. Varios cientos de dólares.

- Se conceden a muy corto plazo, normalmente por un periodo de un año o inferior a un año.

- Los periodos de reposición son muy pequeños y las cantidades devueltas en cada reembolso son, asimismo, muy reducidas. Lo más frecuente es que la devolución del principal más los intereses sea semanal o mensual.

- El tipo de actividades puestas en marcha gracias a este instrumento son microempresas o micronegocios.

- Por último, los recursos prestados, se invierten en actividades libremente escogidas por los propios prestatarios. 


\section{Las instituciones de microcréditos}

\subsection{Tipo de instituciones}

Entre las instituciones que actualmente trabajan en el campo de los microcréditos, se pueden diferenciar dos grandes grupos:

Organizaciones No Gubernamentales (ONGs) y otras organizaciones sin fines de lucro especializadas en programas de microcréditos. Dentro de este grupo, existen muy distintos tipos de instituciones, bien sea por su filosofía, cantidad y origen de los fondos o forma de gestión. No obstante, la característica común de todas ellas, es la utilización de los microcréditos como herramienta para hacer accesible el capital a los más desfavorecidos, siempre con el objetivo de reducir los datos globales de pobreza en el mundo (Carpintero, 1999:113).

Instituciones Financieras, dentro de las que a su vez se puede distinguir entre:

- Instituciones Financieras especializadas en Microcréditos:

- Las instituciones que proceden de una ONG, generalmente conocidas como Instituciones Financieras Graduadas.

- Las cooperativas de crédito.

- Las instituciones financieras filiales de un banco comercial.

- Los bancos comerciales. Son instituciones financieras que pueden operar en el ámbito de los microcréditos, pero que no están especializadas en ellos. Los microcréditos no son el tipo de operaciones en los que la banca basa su negocio.

Si bien es cierto que tradicionalmente los bancos comerciales no han estado dispuestos a prestar dinero a los sectores más pobres de la sociedad, durante los últimos años, dado que ni los prestatarios informales, ni las organizaciones especializadas son capaces de cubrir la ingente necesidad de recursos que demandan los más desfavorecidos, este exceso de demanda ha abierto un atractivo nicho de mercado a las instituciones bancarias. 


\subsection{Características de las instituciones de microcréditos}

Las instituciones que trabajan ofreciendo servicios microfinancieros han modificado las prácticas tradicionales de la banca, eliminando la necesidad de garantías colaterales y creando un sistema bancario basado en la confianza mutua, responsabilidad, participación y creatividad. En comparación, por lo tanto, con las instituciones financieras más tradicionales, las instituciones de microfinanzas poseen unos rasgos que las hacen ser muy innovadoras. Ahora bien, para que una institución de microcréditos sea exitosa y pueda alcanzar los objetivos anteriormente señalados debe de cumplir una serie de requisitos o características:

\subsubsection{Debe conocer el mercado que atiende}

Debe conocer las necesidades, preferencias y limitaciones de su clientela. Los clientes de estas instituciones son aquellos, que aunque poseen capacidad empresarial, son demasiado pobres como para acceder a la banca tradicional. Además, estos clientes poseen unas limitaciones muy específicas. Por ello, es importante que estas instituciones concedan los créditos en las condiciones más adecuadas para este tipo de clientes, por ejemplo:

- No se exigen garantías colaterales, éstas se han sustituido por otras técnicas que motivan la devolución de los préstamos. Entre ellas se pueden encontrar las garantías solidarias, en las que otros responden con sus bienes en lugar del endeudado, las presiones sociales o los requisitos de ahorro (Castelló, 1995). Otra de las técnicas frecuentemente utilizadas, es la promesa de préstamos sucesivos en montos crecientes, generalmente conocidos como los programas de préstamos progresivos. El primer crédito siempre es por una cuantía muy reducida y si el cliente satisface correctamente todos los compromisos asumidos: devolución del principal más los intereses en las fechas indicadas, a dicho cliente se le recompensa pudiendo solicitar nuevos créditos, de montos progresivamente superiores y que le serán concedidos automáticamente (Christen y Wright, 1993). De esta forma, los clientes están muy incentivados a no defraudar a la institución. Gracias a estas técnicas las tasas de morosidad de las instituciones microfinancieras son muy reducidas. En concreto, según un estudio de campo realizado la tasa media de morosidad asciende al 5.2\% (Lacalle, 2002).

- Las transacciones se realizan de la forma más simple posible. Recorde- 
mos que los microcréditos están dirigidos hacia una clientela que por lo general es analfabeta. Por este motivo, los contratos de préstamo son muy sencillos. Suelen ser siempre anuales y con un tipo de interés fijo.

- Las oficinas comerciales se encuentran ubicadas cerca de las localidades donde los prestatarios viven o desarrollan sus actividades. Estos clientes, no solamente suelen vivir en las zonas rurales, bastante distanciados de las grandes ciudades, sino que además, poseen grandes limitaciones de tiempo y de recursos económicos como para desplazarse de forma regular a los grandes centros empresariales. Es muy importante que estas instituciones no se localicen lejos de su clientela.

- Los procedimientos para estudiar y aprobar un nuevo crédito son ágiles y flexibles, lo que permite que el nuevo crédito se pueda otorgar muy rápido, en una o varias semanas. Esto se adapta perfectamente a las condiciones de este sector de la población, que normalmente no pueden asumir una larga espera para recibir el dinero. La mayoría de los programas exitosos de microfinanzas evalúan el riesgo crediticio de acuerdo al conocimiento personal entre el prestamista y el prestatario. Normalmente, un nuevo cliente debe ser recomendado por un cliente antiguo.

\subsubsection{Autosuficiencia financiera}

Toda institución que desee ser viable a largo plazo y no depender de las donaciones externas deberá tener como objetivo la autosuficiencia financiera. Para alcanzar la autosuficiencia, la institución deberá ser capaz de cubrir todos sus costes: los costes de operación, el coste de los fondos (incluyendo el de oportunidad), las provisiones para incobrables y el coste de la inflación. Si además se quiere asegurar el crecimiento futuro de la institución, será necesario incluir también un margen que asegure dicho crecimiento. En la actualidad, solamente las instituciones que están persiguiendo este objetivo son las que están siendo exitosas.

Dadas las características de la clientela de estas organizaciones y el tipo de préstamos concedidos (multitud de pequeñísimos créditos), los costes de transacción y los cargos administrativos son demasiado elevados en comparación a los reducidos ingresos por pago de intereses. En estas condiciones, el principal camino para conseguir la autosuficiencia es la reducción de los 
costes y el establecimiento de los tipos de interés más adecuados.

En cuanto a la reducción de los costes, al gunas de las técnicas innovadoras que estas instituciones utilizan son:

- La utilización de procedimientos de solicitud muy sencillos para nuevos créditos. Generalmente, estas solicitudes no ocupan más de una página.

- La localización de las sucursales de crédito cerca de los clientes y el seguimiento deuna política de concentración geográfica. De esta forma, se consiguen reducir muchos de los costes de transacción.

- La descentralización de la toma de decisiones sobre cualquier nueva operación de crédito, a nivel de las oficinas locales.

- El empleo de sistemas informáticos adecuados para manejar grandes volúmenes de información y de transacciones.

En cuanto a los tipos de interés quese deben establecer, todos los expertos en microfinanzas consideran que las tasas nunca deben estar subsidiadas, pues el dinero regalado lo único que consigue es perpetuar la cultura del no esfuerzo. Al contrario, todos están de acuerdo en que los tipos deben ser aquellos que cubran todos los costes operativos y financieros, aunque esto signifique unos tipos de interés muy superiores a los del mercado. Además, en la mayoría de los casos, los clientes de este tipo de instituciones aceptan estas tasas de interés, pues éstas siguen siendo significativamente inferiores a las cobradas por los usureros, y las prefieren a la ausencia absoluta de crédito por parte del sector formal.

\subsubsection{Importancia del ahorro}

Las instituciones de microcréditos deben reconocer que la prestación de servicios de ahorro es para los pobres tan necesaria como la concesión de servicios de crédito (Rhyne y Otero, 1998). Además, se trata de uno de los elementos más importantes para asegurar el autosostenimiento.

La banca oficial siempre ha creído en el mito de que los pobres son incapaces de ahorrar. Se suponía que los sectores más pobres de la sociedad, no ahorraban porque los escasos recursos de que disponían preferían gastarlos en consumo, de esta manera, las instituciones financieras formales nunca han ofrecido depósitos de ahorro. Por otro lado, los más pobres al no 
disponer de este tipo de servicios se veían obligados a ahorrar en formas no financieras, por ejemplo, mediante la compra de tierras, ganado o guardando el efectivo en sus casas.

Sin embargo, durante las tres últimas décadas, han aparecido extensos estudios sobre el tema que han demostrado la falsedad de estas ideas (Almeyda, 1997; Restrepo y Reichmann, 1995; Adams y Canavesi, 1992; Robinson, 1995 y 1998 y Wisniwski, 1998). La realidad es que en todo el mundo y en to dos los grupos de ingresos, la gente ahorra por motivos tan variados como el consumo, educación, emergencias, inversiones productivas y muchos otros. La gente pobre, tanto las economías domésticas como los pequeños empresarios, ahorran, y cuando no disponen de instituciones financieras seguras lo hacen en formas no financieras.

Hoy se sabe que las economías domésticas pobres y las microempresas desean una cuenta de ahorros segura, localizada cerca de ellos, y de la que puedan ir sacando fondos cuando los necesiten.

Actualmente, habiendo aprendido de los errores del pasado, y con la experiencia de algunos programas exitosos como es el Banco Rakyat de Indonesia, se puede afirmar que los servicios de ahorro de las instituciones de microfinanzas son indispensables, y para que sean efectivos y alcancen a la población destino, deben cumplir las siguientes características:

- Tienen que ser un instrumento de ahorro voluntario y con libre e inmediato acceso a los recursos ahorrados. La liquidez es crucial. La población ahorra para afrontar emergencias y nuevas oportunidades de inversión que pueden surgir en cualquier momento.

- No pueden estar limitados a aquellos que demanden servicios de préstamo.

- Deben ofrecer seguridad y una devolución real positiva.

\section{Los microcréditos y las mujeres}

La pregunta que nos planteamos en este último apartado es: por qué los microcréditos van dirigidos especialmente a las mujeres, por qué la gran mayoría de los clientes de casi todas las instituciones microfinancieras son mujeres. La respuesta, sin lugar a dudas, es que precisamente las mujeres son las más desfavorecidas entre los pobres. Actualmente, todavía siguen sufriendo todo tipo de abusos en todos los rincones del planeta, pero muy 
especialmente en el mundo subdesarrollado. Todavía hoy existen cientos de millones de mujeres analfabetas y de niñas que no pueden terminar la educación básica por tener que ocuparse del cuidado de sus familiares y de las labores del hogar. Todavía hoy existe una marcada discriminación en materia de alimentación y atención sanitaria en favor de los hijos varones. Esta preferencia de invertir más recursos en la salud y la alimentación de los niños que en la de las niñas, se debe a razones esencialmente económicas. Un hijo que crezca sano y fuerte significa una fuente de ingresos y seguridad económica para la vejez de los padres. Sin embargo, el nacimiento deuna niña es una carga económica que no reportará ningún beneficio a los padres. Así, en muchos países se deja de amamantar a las niñas mucho antes que a los niños y se las alimenta menos y con una dieta más pobre. Todavía hoy muchas mujeres están desempleadas, ocupadas en el sector informal de la economía o en puestos inadecuados y/o mal pagados. En estas condiciones, estas mujeres tienen muy pocas posibilidades de ahorrar, invertir o pedir un crédito, y por lo tanto, de tener esperanzas para su futuro. Según datos de Naciones Unidas (1995b), aun cuando las mujeres representan más del 50\% de la población mundial, aportan solamente una tercera parte de la fuerza laboral oficial, cifra que según las proyecciones de la Oficina Internacional del Trabajo será superior en el año 2000. Cumplen con las dos terceras partes de todas las horas de trabajo en el mundo, siendo su aportación laboral tanto en el sector organizado como en el informal superior a la del hombre, aún así, la mujer no recibe una parte equitativa de los bienes e ingresos mundiales. Aunque las mujeres trabajan más horas que los hombres en los campos, no tienen control sobre las cosechas, y normalmente, tienen menos comida para ellas y para alimentar a sus hijos. De estos datos, se deduce que hoy en día, las mujeres están todavía marginadas de los recursos económicos, sociales y políticos de sus países.

Ahora bien, los microcréditos no se dirigen especialmente a las mujeres sólo porque éstas son las que cumplen la mayoría de las veces los requisitos de elegibilidad; también existen otros motivos. En primer lugar, se ha comprobado que las mujeres son capaces de derivar mayores beneficios económicos para los integrantes de sus familias que los hombres. Según los datos de distintos países: Filipinas, Camerún, India, Líbano y Nepal, los ingresos administrados por la madre se reinvierten mucho más en el bienestar de la familia que los administrados por el padre. Concretamente, las mujeres aportan entre el 40 y $60 \%$ del ingreso familiar para la supervivencia y el bienestar de la familia. 
Otra razón tiene que ver con la importancia adquirida por la búsqueda de la autosuficiencia institucional. Entre los principales objetivos de las instituciones de microcréditos se encuentra la viabilidad financiera. Este objetivo, unido al hecho de que las tasas de devolución de los créditos son superiores entre las mujeres que entre los hombres, ha dado lugar a que la gran mayoría de las instituciones hayan preferido dirigirse hacia las mujeres. En concreto, según un estudio de campo realizado por la autora ${ }^{2}$, se puede afirmar con un grado de confianza del $98 \%$ que cuanto mayor es el número de clientes femeninas que posee una institución menor es su tasa de morosidad.

Por último, a todo lo anterior, hay que añadir que, durante las últimas décadas, el principal objetivo de las agencias donantes, muchas de ellas instituciones internacionales para el desarrollo, ha sido reducir las desigualdades entre hombres y mujeres. Una gran parte de estas agencias han presionado a las instituciones microfinancieras para que más del $50 \%$ de sus servicios fueran dirigidos hacia las mujeres (Hulme y Mosley, 1996).

En conclusión se puede afirmar que el motivo fundamental por el que los microcréditos se dirigen especialmente a las mujeres, es porque representan una oportunidad económica para miles de mujeres, incapaces de conseguir una oportunidad en un mundo dominado por los hombres. Oportunidad económica que además saben utilizar eficientemente, consiguiendo mejorar su nivel de bienestar y el de sus familias. Los reducidos montos de capital y la escasa capacitación requerida para poner en marcha una microempresa, han favorecido de forma especial la integración de la mujer en las instituciones microfinancieras. En las zonas rurales, las mujeres elaboran y venden alimentos, cultivan determinados productos y fabrican productos artesanos con materias primas locales. En las ciudades, las mujeres trabajan fundamentalmente como vendedoras ambulantes. Aunque se trata de trabajos que muchas veces generan ingresos reducidos, también es cierto, que en la mayoría de las ocasiones, es la única posibilidad económica que se les presenta, debido a los muchos obstáculos con que se encuentran a lo largo de sus vidas.

El resultado de la prestación de los servicios microfinancieros está demostrando ser efectivo en la lucha contra la pobreza, permitiendo un desarrollo sostenido, a través de la implantación de pequeñas empresas o negocios, que generan los ingresos suficientes como para que el prestatario

2 Véase M. Lacalle (2002), capítulo 8. 
pueda ir devolviendo el principal más los intereses, incrementar el nivel de vida de su familia (poder comer más de una vez al día) y además poder ahorrar parte de dichos ingresos. Aunque la tasa de ahorro sea muy reducida, es la que le permitirá poder expandir su pequeño negocio en el futuro. Además, los microcréditos no sólo son capaces de incrementar los ingresos y los ahorros, también estimulan la autoestima y confianza de los prestatarios en sí mismos, cuando descubren que pueden adquirir, invertir y devolver un préstamo.

\section{Bibliografía}

Adams, D.W. y Canavesi, M.L. (1992), "Rotating Savings and Credit Associations in Bolivia", en Dale, W. A. y Delbert, A. F. (eds.), Informal Finance in LowIncome Countries, Boulder, Colorado, Westwiew Press.

Alarcón Costa, C. (1990), Sector Informal: ¿Problema o solución?, Quito, Fundación Ecuatoriana de Desarrollo.

Almeyda, G. (1997), Dinero que cuenta: Servicios financieros al alcance de la mujer microempresaria, Washington, D.C., Banco Interamericano de Desarrollo.

Aslanbeigui, N.; Pressman, S.; Summerfield, G. (1995), Mujeres en tiempos de transformaciones económicas, Madrid, Ediciones NARCEA.

CARPINTERo, S. (1999) , "Panorama general del microcrédito en América Latina”, Revista de Cooperación Internacional, Vol. 2, pp. 103-124.

CAStelló, C. (1995), "Servicios financieros a la microempresa: Lecciones y perspectivas, Síntesis Revista de Ciencias Sociales Iberoamericanas, № 23, Enero-J ulio, pp. 91-99.

CEPAL (1993), Feminización de la pobreza en América Latina y el Caribe, Santiago de Chile, Comisión Económica para América Latina y el Caribe.

Christen, R. y WRIGHT, S. (1993), “Chile: Financiamiento de la microempresa. Viabilidad de la creación de un mecanismo financiero formal", en MezzerA, J. (ed.), Crédito Informal: Acceso al Sistema Financiero, Chile, PREALC.

González-Vega, C. (1996), "Introducción”, en Otero, M. y Rhyne, E. (eds.), El nuevo mundo de las finanzas microempresariales, México, Plaza y Valdés Editores. 
Hossain, M. (1988), Credit for alleviation of rural poverty: The Grameen Bank in Bangladesh, Research Report 65, Washington, D.C., International Food Policy Research Institute.

Hulme, D. y Mosley, P. (1996), Finance against poverty, London, Routledge.

Hunt, P., Williams, C. y Donaldson, G. (1982), Financiación básica de los negocios, México, UTEHA.

J olis, A. (1996), "The Good Banker", The Independent, Sunday Suplement, 5 May.

Labie Lebon, M. y Sota Ramos, J. (1998), "La creación de instituciones de microfinanzas: ¿una elección con riesgo?", Boletín del ICE, nำ2570, pp. 31-39.

Lacalle, M. (2002), Microcréditos. De pobres a microempresarios, Barcelona, Ariel Social, 231 págs.

LiedHolm, C. y MeAd, D. (1987), Small scale industries in developing countries: Empirical evidence and policy implications, Michigan, Michigan State University, East Lansing.

LyCETTE, M. y White, K. (1988), "Acceso de la mujer al crédito en América Latina y el Caribe", en Berger, M. y Buvinic, M. (coords.), La mujer en el sector informal: Trabajo femenino y microempresa en América Latina, Venezuela, Nueva Sociedad.

Mezzera, J. (1998), "Excedente de la oferta de trabajo y sector informal urbano", en Otero, M. y Rhyne, E. (eds.), El nuevo mundo de las finanzas microempresariales, México, Plaza y Valdés Editores.

Naciones Unidas (1995a), La mujer en una economía mundial en evolución, Nueva York: Departamento de Coordinación de Políticas de Desarrollo Sostenible, Naciones Unidas.

Naciones Unidas (1995b), The World's Women 1995: Trends and Statistics, New York, Naciones Unidas.

Restrepo, E. y Reichmann, R. (1995), Balancing the double day: Women microentrepreneurs as managers, Cambridge, M.A., Accion Internacional.

Rhyne, E. y Otero, M. (1998), "Servicios financieros para microempresas: Principios e instituciones", en Otero, M. y RHYNe, E. (eds.), El nuevo mundo de las finanzas microempresariales, México, Plaza y Valdés Editores.

Robinson, M. (1998), “Movilización de ahorros y fondos microempresariales: La experiencia Indonesia", en Otero, M. y RHYne, E. (eds.), El nuevo mundo 
de las finanzas microempresariales, México, Plaza y Valdés Editores.

Robinson, M. (1995), "Indonesia: The role of savings in developing sustainable comercial financing of small and micro enterprise", en BRUGGER, E.A. y Rajapatirana, S. (eds.), New Prespectives on Financing Small Business In Developing Countries, New York, ICS Press.

SethuRaman, S.V. (1988), "El sector informal urbano y las políticas de desarroIlo", en SANCHís, E. y MiÑANA, J . (eds.), La otra economía: Trabajo negro y sector informal, Valencia: Edicions Alfons el Magnanim, Institució Valenciana D'estudis i investigació.

Teka Aregau, G. (1997), El papel del crédito agrícola en el desarrollo agrario en Etiopía, Tesis Doctoral presentada en la Universidad Autónoma de Madrid el 3 de julio de 1997.

WISNIWSKI, S. (1998), Savings in the context of microfinance, Ponencia presentada en el Foro Interamericano sobre Microempresa, Ciudad de México, marzo 1998. 